Revista Oficial del Poder Judicial

ÓRGANO DE INVESTIGACIÓN DE LA CORTE SUPREMA DE JUSTICIA DE LA REPÚBLICA DEL PERÚ

Vol. 13, n. ${ }^{\circ} 15$, enero-junio, 2021, 163-183

ISSN versión impresa: 1997-6682

ISSN versión online: 2663-9130

DOI: 10.35292/ropj.u13i15.393

\title{
La ficha de valoración de riesgo y su valor probatorio en las audiencias de medidas de protección por violencia de género
} \author{
for gender violence \\ 0 (2) \\ JULIA ELEANOR JARA CARRERA \\ Corte Superior de Justicia de Lima Este \\ (Lima, Perú) \\ Contacto:jjarac@pj.gob.pe \\ https://orcid.org/0000-0003-2637-7765
}

The risk assessment form and its probative value in the hearings of protection measures

\begin{abstract}
RESUMEN
Dentro de las audiencias de medidas de protección, la ficha de valoración de riesgo de mujeres víctimas de violencia contra la mujer es considerada, en muchas ocasiones, de forma aislada; además de tenerse en cuenta como el único sustento, sin valorar otros medios de prueba para fundar la medida de protección.

Palabras clave: ficha de valoración de riesgo; medidas de protección; valor probatorio.
\end{abstract}




\section{ABSTRACT}

Within the hearings for protection measures, the risk assessment form for women victims of violence against women is often considered in isolation; in addition to being taken into account as the only support, without evaluating other means of evidence to support the protection measure.

Key words: risk assessment form; protective measures; evidentiary value.

\section{Recibido: 13/04/2021 Aceptado: 16/04/2021}

\section{PROBLEMA}

El origen de la ficha de valoración de riesgo se encuentra en el Decreto Supremo n. ${ }^{\circ}$ 009-2016-MIMP, que reglamenta la Ley n. ${ }^{\circ} 30364$, «Ley para prevenir, sancionar y erradicar la violencia contra la mujer e integrantes del grupo familiar», decreto que fue publicado el 27 de julio de 2016. Este instrumento ha facilitado la obtención de información al juzgador para conocer la situación de riesgo que tiene la víctima de violencia de género, mediante la ficha de valoración de riesgo, regulada en la norma mencionada.

No obstante el valioso aporte que ha significado dicha ficha para determinar el riesgo de los afectados y dotarlos de medidas de protección fundamentadas con la sola elaboración de la ficha, se ha generado controversia respecto a la fiabilidad que puede originar en el juzgador al momento de imponer medidas de protección y ha sido cuestionada como un documento simple sin mayor valor probatorio. 


\section{DESARROLLO}

\subsection{Las formas que puede adoptar la violencia de género}

La Convención Interamericana para Prevenir, Sancionar y Erradicar la Violencia Contra la Mujer, conocida como Convención de Belém do Pará, en el artículo 3, capítulo II, establece que «Toda mujer tiene derecho a una vida libre de violencia, tanto en el ámbito público como en el privado» (OAS, 1994). En ese mismo sentido, la Convención sobre la Eliminación de Todas las Formas de Discriminación contra la Mujer ha señalado en su artículo 1 que:

la expresión «discriminación contra la mujer» denotará toda distinción, exclusión o restricción basada en el sexo que tenga por objeto o resultado menoscabar o anular el reconocimiento, goce o ejercicio por la mujer, independientemente de su estado civil, sobre la base de la igualdad del hombre y la mujer, de los derechos humanos y las libertades fundamentales en las esferas política, económica, social, cultural y civil o en cualquier otra esfera (Naciones Unidas, 1979).

De igual manera, la Declaración Universal de Derechos Humanos en el artículo 1 dispone que «Todos los seres humanos nacen libres e iguales en dignidad y derechos y, dotados como están de razón y conciencia, deben comportarse fraternalmente los unos con los otros» (Naciones Unidas, 1948); por ende, estando a dichos instrumentos internacionales los Estados, entre ellos el Perú, deben adoptarse las medidas ordenadas por el Comité para la Eliminación de la Discriminación contra la Mujer, entre ellas las medidas para erradicar la violencia contra la mujer.

Respecto a las formas de violencia contra la mujer, la ONG Ayuda en Acción (2017) ha realizado una clasificación didáctica de estas, que se detalla a continuación: 
a) Violencia física

Aquella acción voluntaria que deja huellas en la integridad física de la víctima de forma temporal o permanente, ello dependerá de la magnitud del daño que se ocasione.

b) Violencia psicológica

Este tipo de violencia tiene como finalidad desvalorizar a la mujer, atacando su autoestima y amor propio mediante insultos, vejaciones, improperios, humillaciones, entre otros, que dejan una afectación en las emociones de la víctima.

c) Violencia sexual

Conlleva a forzar a una persona a mantener relaciones sexuales sin su consentimiento; y en el caso de menores o personas con incapacidad de resistir o colocados en una situación que les impida dar su libre voluntad o consentimiento.

\section{d) Violencia económica}

Este tipo de violencia busca menoscabar los recursos económicos, a fin de coaccionar a la víctima o colocarla en una situación de desventaja ante su agresor, dañando su integridad.

\section{e) Violencia patrimonial}

Este tipo de violencia busca atentar contra el patrimonio de la víctima, con la finalidad de afectarla psicológicamente o ejercer sobre esta una posición de poder que la doblegue a obedecerle indubitablemente, bajo un supuesto de consentimiento viciado.

\section{f) Violencia social}

Acciones tendientes a aislar socialmente a la víctima, con la finalidad de alejarla de sus familiares y amigos para colocarla en un estado de indefensión absoluta que impide que solicite ayuda a personas de su confianza o amistades cercanas. 


\section{g) Violencia vicaria}

El nivel de violencia va más allá de la víctima que puede ser pareja o expareja, sino que busca lastimar en un extremo tal que podría matar a su hijo con tal de dañar a la víctima.

Consecuentemente, se aprecia que existen múltiples formas de violencia contra las mujeres, lo cual es un catálogo abierto que admite nuevas modalidades, pues conforme avanza la tecnología y la informática, nuevas formas de violencia aparecerán en la sociedad. En un inicio estas pasarán inadvertidas como atentatorias a la dignidad de la mujer; por ello es necesario estar alertas a las nuevas tendencias ocultas de violencia contra la mujer, a fin de eliminar esta forma de discriminación a los derechos que tiene de igual manera que un hombre.

\subsection{Respuesta del Poder Judicial ante la violencia de género}

Conforme lo ha explicado didácticamente Delgado (2020), la respuesta de parte del Estado debe ser integral, es decir, en todos los ámbitos que impliquen afectación a la víctima de violencia, a fin de evitar la reiterancia delictiva y que se generen mayores daños en esta, pues conforme a los instrumentos internacionales antes mencionados, se ha visto por conveniente prevenir la violencia, ya que esta atentaría contra los derechos humanos que tiene una mujer. Así, Delgado (2020) señala tres niveles de prevención:

\section{a) Prevención primaria}

Atiende a las causas de la delincuencia actuando sobre la comunidad para resolver el conflicto social que daría lugar al delito.

b) Prevención secundaria

Actúa cuando se ha manifestado el conflicto social, para evitar que tenga lugar el delito. En este nivel se considera la victimización, por la cual se tiene en consideración a las víctimas potenciales o en situación de riesgo (especialmente vulnerables). 


\section{c) Prevención terciaria}

Actúa cuando ya se ha producido el delito, para evitar que tenga lugar otro delito. En este sentido, partiendo de la victimización se considera a la propia víctima que ha sufrido el delito para evitar la victimización reiterada.

Con estos niveles se busca desde evitar la violencia hasta evitar la reiterancia delictiva. Cabe precisar que al estar en un nivel primario de prevención, las actuaciones preliminares muchas veces carecen de un acervo probatorio que permita determinar el peligro o riesgo que acontece a la víctima de violencia. Por ello se implementó la ficha de valoración de riesgo, para conocer bajo un estándar preestablecido el riesgo concreto que presenta la víctima.

\subsection{Victimización secundaria y sus principales elementos}

En este punto juegan un rol importante los funcionarios y los servidores del Estado que atienden a las usuarias de violencia de género, ya que al presentar vulnerabilidad ante eventos de violencia, se deberá evitar un trato desatinado o una dilación en el proceso de ser el caso. Esto resulta relevante si se pretende que la víctima confíe en las autoridades e informe espontáneamente lo sucedido, lo cual tiene mayor implicancia cuando en nuestro sistema de justicia se cuenta con una ficha de valoración de riesgo en donde la víctima será el actor principal de la información que se brinde en dicho documento.

Para mejor precisión del término esbozado, cabe tomar una cita de Gutiérrez de Piñeres, Coronel y Pérez (2009) en la que se señala que:

Muchos autores coinciden en definir la victimización secundaria como las consecuencias psicológicas, sociales, jurídicas y económicas negativas que dejan las relaciones de la víctima con el sistema jurídico penal, supone un choque frustrante entre las legítimas 
expectativas de la víctima y la realidad institucional, involucrando una pérdida de comprensión acerca del sufrimiento psicológico y físico que ha causado el hecho delictivo, dejándolas desoladas e inseguras y generando una pérdida de fe en la habilidad de la comunidad, los profesionales y las instituciones para dar respuesta a las necesidades de las mismas (p. 50).

En opinión de la estudiosa Cuesta (2014, p. 54), la participación de la persona ofendida en el proceso penal supone alta carga de estrés postraumático, pues el revivir el hecho una y otra vez produce constantemente su victimización.

Como elementos de la victimización secundaria tenemos a una persona ofendida por un delito de violencia de género y a los servidores y funcionarios del aparato estatal (Ministerio Público, Policía, Poder Judicial) que investigan e imparten justicia en el caso concreto, y que se presentan en los momentos en que la víctima se encuentra presente, en la etapa de investigación, intermedia y juicio, incluso en segunda instancia. En ese sentido, se advierte como estos momentos: durante la interposición de la denuncia, al momento de rendir la declaración, la atención en salud, el juicio, la sentencia, y en diferentes niveles: judicial, familiar, social y laboral (Gutiérrez de Piñeres, Coronel y Pérez, 2009, p. 52).

A manera de precisión, es necesario señalar que los funcionarios y los servidores del Estado que tengan contacto con las víctimas de violencia de género, deben evitar revictimizarlas. Para ello es útil la implementación de protocolos destinada a cada actuación que se realizará, además de distinguir a los diferentes sujetos vulnerables que se presentan como niños, adolescentes, mujeres, ancianos, entre otros. Por ende, de evitarse este tipo de violencia, conseguiremos no solo que la sociedad confíe más en la administración de justicia, sino promoveremos que ninguna víctima guarde silencio ante eventos delictivos que denigran su dignidad como persona. 


\subsection{La victimización reiterada}

Varona, De la Cuesta, Mayordomo y Pérez (2015, p. 42) señalan que aunque puede darse en cualquier tipo de víctimas, aquellas socialmente vulnerables experimentan en mayor grado el fenómeno de la revictimización o victimización reiterada, desde perspectivas cualitativas, temporales o espaciales.

Llamada también revictimización, en ese sentido la Sociedad Vasca de Victimología (s. f.) precisa que se presenta cuando una misma víctima sufre más de una victimización (generalmente) del mismo tipo. A mayor vulnerabilidad, mayor probabilidad de sufrir una revictimización, que atiende a factores situacionales, personales o relacionales.

Con lo mencionado, se aprecia que existe una vinculación muy estrecha entre la situación de vulnerabilidad de la víctima y el grado de victimización, es decir, cuanto más vulnerable sea una persona, mayor será la posibilidad de ser revictimizada por el agresor. Por tanto, es imprescindible realizar preliminarmente un diagnóstico del riesgo que atraviesa la víctima si el Estado no la protege, pues cada persona varía en dicho riesgo y como tal deberán tomarse las medidas necesarias para evitar un daño irreparable o aún mayor. El papel del Estado es el de garantizar la efectiva protección de los derechos fundamentales de toda persona humana conforme lo establece el artículo 1 de la Constitución Política del Perú, por ello su respuesta deberá ser inmediata e integral, puesto que es un deber ineludible.

\subsection{Protección y apoyo a La víctima}

El profesor Delgado (2020) resalta la importancia de proteger a la víctima en todos sus niveles, a fin de darle eficacia a la protección de los derechos fundamentales tales como la vida, la integridad física, psicológica, psíquica y moral de la mujer. En ese sentido, 
señala que el Estado mediante sus entidades públicas deberá evitar la victimización, y enumera una serie de acciones a fin de proteger y apoyar a la víctima:

a) Mitigar la victimización primaria: mediante el pago de una reparación civil y una adecuada asistencia permanente a la víctima.

b) Evitar la victimización secundaria: brindándole seguridad e información de sus derechos, y que sea escuchada en audiencia, a fin de conocer sus necesidades, ello en correspondencia con la dignidad que le asiste por ser una persona humana.

c) Evitar la victimización reiterada: mediante la imposición de medidas de protección a la víctima provisionales o definitivas, las cuales deberán tener en cuenta el diagnóstico de la situación de riesgo.

d) Asistencia para restablecimiento: en la cual deberá actuar el equipo multidisciplinario, a fin de brindar la asistencia que requiera la víctima de acuerdo con sus necesidades.

e) Apoyando a la víctima de violencia: mediante el apoyo para su empoderamiento, brindando información sobre apoyo y protección, conociendo las necesidades de víctimas vulnerables y la protección de los hijos en custodia/visita.

De estas acciones, resaltan las medidas de protección que deberán derivar de la situación de riesgo de la víctima, bajo una predicción de la conducta del agresor. Al respecto, la fuente de dicha situación objetivamente no podría basarse solo en una declaración unilateral, como se puede apreciar de la ficha de valoración riesgo, en donde se consigna información de parte (víctima). Ello no es negativo, de ningún modo, pero se asumiría una postura subjetiva si es el único fundamento de la medida de protección. 


\subsection{La medida de protección y su naturaleza jurídica}

El Tribunal Constitucional del Perú (2020) ha establecido que las mujeres tienen derecho a una vida libre de violencia. Así, ha precisado que la medida de protección es idónea, e incluso no podría, desde la perspectiva del imputado, vulnerar el derecho a la defensa, conforme se precisa a continuación:

Garantizar a las mujeres su derecho a una vida libre de violencia es de suma importancia para el Estado y es por ello que ha regulado las medidas de protección como un mecanismo idóneo para alcanzar ese objetivo. En consecuencia, la intervención que se produce en el derecho de defensa del agresor cuando la judicatura dicta tales medidas de protección es menor si se compara con la satisfacción del derecho a una vida libre de violencia que se alcanza. Para este Tribunal la intervención en el derecho de defensa del agresor no resulta desproporcional ni irrazonable (fundamento 93).

En ese orden de ideas, el Poder Judicial del Perú ha definido la naturaleza jurídica de la medida de protección. La Segunda Sala Civil de Trujillo, de la Corte Superior de Justicia de La Libertad, en el Expediente n. ${ }^{\circ}$ 05098-2017-93-1601-JR-FC-02 ha establecido que:

La naturaleza jurídica de las medidas de protección es que constituyen un proceso sui generis de tutela urgente y diferenciada, que tiene carácter sustantivo, representando así un medio autónomo, a través del cual se pretende cesar la violencia, salvaguardando en forma inmediata, célere y eficaz la integridad psicofísica, la dignidad, la libertad de las personas integrantes del grupo familiar, como también el lograr la recomposición del grupo familiar, como también en lo personal en el caso de las mujeres (fundamento 4.3). 
En tal sentido, la legislación ha establecido plazos acordes a la urgencia que se requiera, luego de verificarse el nivel de riesgo según la ficha de valoración de riesgo. Márquez (2018) ha sintetizado ello:

El EXP. 00120-2016-0-0901-JR-FC-03 hace referencia a los principios rectores de la Ley 30364, priorizando el principio de Celeridad procesal, puesto que se busca evitar dilaciones en los procesos de [sic] El proceso especial de violencia contra las mujeres e integrantes del grupo familiar se realiza teniendo en cuenta lo siguiente:

a) En caso de riesgo leve o moderado, identificado en la ficha de valoración de riesgo, el juzgado de familia, en el plazo máximo de cuarenta y ocho (48) horas, contadas desde que toma conocimiento de la denuncia, evalúa el caso y resuelve en audiencia la emisión de las medidas de protección y/o cautelares requeridas, que sean acordes con las necesidades de la víctima.

b) En caso de riesgo severo, identificado en la ficha de valoración de riesgo, el juzgado de familia, en el plazo máximo de veinticuatro (24) horas, contadas desde que toma conocimiento de la denuncia, evalúa el caso y emite las medidas de protección y/o cautelares requeridas, que sean acordes con las necesidades de la víctima. En este supuesto el Juez puede prescindir de la audiencia.

La audiencia es inaplazable y se realiza con los sujetos procesales que se encuentren (p. 84).

Además, la tutela diferenciada es definida por la Real Academia Española (s. f.) como el procedimiento especial para la protección de derechos materiales privilegiados. Por ello en las medidas de protección el derecho privilegiado prevalece; atendiendo al estado de vulnerabilidad son protegidos por encima inclusive de otros derechos. 


\subsection{Definición y regulación normativa de la ficha de valoración de riesgo}

Mateo (2020) define a la ficha de valoración de riesgo como:

La herramienta que debe ser usada por los responsables del sistema de justicia para definir la gravedad del riesgo, así como evitar la revictimización, dictar medidas de protección, sancionar al agresor/a, prevenir posibles feminicidios en caso de las mujeres y prevenir todo tipo de violencia contra algún integrante de la familia (p. 20).

El instructivo de las fichas de valoración de riesgo es llenado por los operadores cuando reciben la denuncia; no obstante, tiene ciertas deficiencias en cuanto a la persona que lo emite, así como en la información que contiene, tal como sigue:

a) El juez no realiza ningún análisis sobre quién hace la evaluación en la ficha de valoración de riesgo, ya que al ser evaluada por un personal que no es especialista o no es licenciado en Psicología le resta verosimilitud y la verdad de los hechos (Mateo, 2020, p. 70).

b) «El espacio que consta en la ficha para añadir observaciones de interés adicionales $[\ldots]$ es sumamente pequeño para redactar los datos relevantes que la víctima quisiera que se tomen en cuenta, así como también de la información de cómo percibe a la víctima, la autoridad policial» (Navarro, 2020, p. 22).

En cuanto a la legislación en la materia, el artículo 28 de la Ley n. ${ }^{\circ}$ 30364, modificado mediante el Decreto Legislativo n. ${ }^{\circ} 1386$ establece que:

En casos de denuncias por violencia contra las mujeres y los integrantes del grupo familiar, la Policía Nacional del Perú, el Ministerio Público o el Poder Judicial aplican la ficha de valoración 
de riesgo, que corresponde a cada caso. También deben aplicarla cuando toman conocimiento de violencia durante el desempeño de otras funciones.

La Policía Nacional del Perú y el Ministerio Público deben remitir la ficha de valoración de riesgo al juzgado de familia, conforme al proceso regulado en la presente ley, el cual la evalúa para su pronunciamiento sobre las medidas de protección y cautelar y debe ser actualizada cuando las circunstancias lo ameritan, lo que incluye la posibilidad de variar la evaluación de riesgo.

De esta manera, se aprecia una regulación taxativa que la delimita dentro del ámbito del dictado de medidas de protección y cautelar, es decir, a fin de atender inmediatamente los casos de violencia que ameriten atención oportuna por el Estado. Estas fichas son tres: la ficha de valoración de riesgo en mujeres víctimas de violencia de pareja, la ficha de valoración de riesgo en niños, niñas y adolescentes víctimas de violencia familiar y la ficha de valoración de riesgo en personas adultas víctimas de violencia familiar.

Se debe precisar que nuestra legislación hace hincapié en la atención urgente en los casos severos ( 1 y 2), ya que este nivel de violencia implica una alta probabilidad de un perjuicio extremo que podría acabar con su vida o tentar con ponerle fin, más aún en los casos de violencia de pareja, donde median relaciones en las cuales la víctima está en un contexto íntimo con el agresor.

\subsection{Aporte de la ficha de valoración de riesgo a la protección de Las víctimas}

A través de su implementación, la ficha de valoración de riesgo en nuestra legislación ha permitido que los casos de violencia contra las mujeres se atiendan céleremente y por ende se dicten las medidas de protección necesarias de acuerdo con el riesgo presente y concreto, en sus cuatro niveles: leve, moderado, severo 1 y severo 2. En esta línea, se ha arribado a las siguientes conclusiones en el informe emitido por la Defensoría del Pueblo (2017): 
El principal avance que aporta la norma es la celeridad en el otorgamiento de las medidas de protección y cautelares a favor de la víctima. Además de las pruebas que se puedan aportar durante la denuncia, se ha incluido la aplicación de una ficha de valoración del riesgo que permita determinar la gravedad de la situación en cada caso, a fin de adoptar todas las medidas necesarias para evitar mayores daños a la vida y salud de la denunciante y su entorno familiar (p. 24).

Si bien los estereotipos tienen más aspectos negativos en violencia de género, también es de rescatarse el aporte que representan para detectar cualidades de los hombres que permiten advertir una amenaza potencial (Cardoso, 2015).

De acuerdo con lo señalado, es necesario llenar correctamente dicha ficha para obtener información de calidad que permita tomar decisiones según el caso concreto, por lo que es importante que la persona encargada de su llenado esté debidamente capacitada.

\section{9. ¿La ficha de valoración de riesgo es suficiente para conocer el riesgo de la víctima de violencia de género?}

Las normas internacionales, en aras de la protección de los derechos fundamentales de las mujeres, han establecido que la valoración del riesgo de la víctima es prioritaria de atención por las autoridades de los Estados y que deben realizar las implementaciones de medidas necesarias y urgentes en los casos concretos que se presenten, a fin de evitar la reincidencia.

En ese sentido, el Consejo de Europa (2011), en el Convenio de Ginebra, exhorta a los Estados parte a que regulen dentro de sus legislaciones lo siguiente:

Artículo 51. Valoración y gestión de riesgos

1 Las Partes adoptarán las medidas legislativas o de otro tipo necesarias para que todas las autoridades pertinentes puedan llevar a 
cabo una valoración del riesgo de letalidad, de la gravedad de la situación y del riesgo de reincidencia de la violencia a efectos de gestionar el riesgo y garantizar, en su caso, la coordinación de la seguridad y el apoyo.

Consecuentemente, por sí sola, la ficha de valoración de riesgo no es determinante para establecer que la víctima tenga un riesgo al que se arribe en sus conclusiones, más aún si el diagnóstico del riesgo de un proceso, en palabras del profesor Delgado (2020), requiere de cuatro niveles:

1. Elección de datos objetivos relevantes (indicadores).

2. Aprehensión de los datos objetivos.

3. Valoración de la información: decisión sobre el riesgo.

4. Suministro de la decisión a quien deba decidir.

\subsection{Propuesta de solución}

El órgano jurisdiccional, en atención a tomar acciones positivas a fin de evitar una vulneración de derechos fundamentales de la mujer, tiene que procurar, sin dilaciones, que los hechos denunciados no se vuelvan a repetir, lo cual es legítimo si buscamos frenar la violencia de género (Mertens de Wilmars, s. f.).

De este modo, la Corte Superior de Justicia de La Libertad (2019) ha establecido:

La ficha de valoración de riesgo es una herramienta técnica que permite al juez tener una óptica más amplia del problema familiar en sí, determinando el nivel de violencia que se encuentra ejerciéndose sobre la víctima - en grado de probabilidad -, lo que le permite hacer una predicción sobre las posibilidades de que en el futuro se reiteren situaciones de violencia, teniendo dicho documento un carácter presuntivo. Esta ficha permite tener elementos más óptimos para dictar las medidas de protección urgente según 
la naturaleza del problema, ya que ubica el grado de violencia aparentemente existente: leve, moderado o de alto riesgo (fundamento 5.4.3).

De lo mencionado, se aprecia que la Corte Superior de Justicia de La Libertad es de la posición de atribuirle un carácter presuntivo a la ficha de valoración de riesgo, es decir, tiene cierta fiabilidad, salvo sea contradicha por alguna pericia especializada, como la psicológica, el certificado médico legal, etc. A su consideración, dicho documento es importante porque resulta un sustento válido para la imposición de medidas de protección y cautelares, que por su naturaleza no son definitivas sino temporales, esto es, que pueden ser modificadas o anuladas en el transcurso del proceso.

Del mismo modo, en un pronunciamiento reciente, el Tribunal Constitucional peruano (2020), como supremo intérprete de la Constitución, ha señalado:

Dado que la «Ficha de valoración de riesgo» es un instrumento objetivo que ayuda a establecer cuál es el tipo de riesgo de violencia existente (leve, moderado o severo), así como a determinar cuáles de las medidas de protección reguladas por el artículo 22 de la Ley 30364 serán las más idóneas para proteger a la víctima de violencia, no se admite que el agresor participe de la diligencia donde se aplica el cuestionario contenido en dicha ficha porque su presencia se torna impertinente; ya que podría influenciar la espontaneidad de las respuestas que otorgue la víctima, distorsionando así los resultados que se obtengan de la evaluación del riesgo y propiciando, además, la revictimización a través de los cuestionamientos a las respuestas (fundamento 47).

Con ello deja en claro que si bien la ficha de valoración de riesgo es declarativa, es decir, unilateral, no afecta el derecho a la defensa, pues un escenario en que se permita la presencia de la parte agresora en dicha diligencia, solo le restaría credibilidad a la agraviada, ya 
que la víctima puede verse intimidada con su presencia, y por ende la información que proporcione podría no ajustarse a la realidad, por el temor u otra emoción negativa hacia su agresor.

Comparto la propuesta formulada por Navarro (2020), quien sostiene que en su oportunidad deberá remitirse al juzgado de familia competente no solo la ficha de valoración de riesgo, sino que esta debe ir acompañada con el informe psicológico, ya que ambos se expiden inmediatamente; el primero por el que reciba la denuncia - Policía Nacional del Perú, Ministerio Público y Poder Judicial-y el segundo por el psicólogo del Centro de Emergencia (Ministerio de la Mujer y Poblaciones Vulnerables), ello con la finalidad de darle más solidez a la ficha de valoración de riesgo, considerándose que el riesgo severo debe atenderse en un término de 24 horas.

Asimismo, la Tercera Sala Civil de la Corte Superior de Justicia de La Libertad, en el Expediente n. ${ }^{\circ}$ 9448-2017-70-1601-JR-FC-02, establece tomar en consideración todos los medios de prueba que se tenga a la vista, así como las circunstancias del caso concreto, como a continuación se aprecia:

La naturaleza jurídica en comento necesariamente obliga a que, para su dictado, el juez de Familia se guíe por criterios de razonabilidad, en función a la situación fáctica de violencia vivida, debiendo cubrir «todos los aspectos de violencia expuestas de los medios probatorios que se adjunta a la solicitud de medida de protección» presentada ante el Juzgado (el cese de la violencia ejercida y la restitución de los vínculos afectivos entre los miembros del grupo familiar); lo contrario - la omisión de pronunciarse sobre un aspecto de la violencia o no cubrir íntegramente el hecho de violencia misma- implicaría incumplir la función tutelar que busca la Ley 30364 (fundamento 4.7.1).

Lo señalado contribuiría a otorgarle mayor sustento al valor probatorio que se pretende meritar al momento de imponerse las 
medidas de protección que se requieran por eventos de violencia contra la mujer, y darle mayor motivación a la resolución que se emita. Ello en aras de no perjudicar el debido proceso por la atención prioritaria a la víctima de violencia; y así lograr un equilibrio entre la justicia y la debida protección de la víctima para garantizar su derecho a vivir libre de violencia.

\section{CONCLUSIONES}

1. La ficha de valoración de riesgo por sí sola no es suficiente para determinar el nivel de riesgo que se presenta en cada caso. Se requieren otras pericias tales como el certificado médico legal o la pericia psicológica correspondiente; asimismo, deben valorarse las circunstancias de hechos denunciados, para contextualizarlos de tal manera que se pueda realizar una prognosis de la conducta del agresor.

2. La ficha de valoración de riesgo, al sustentar las medidas de protección, no vulnera el derecho de defensa del agresor, pues son medidas temporales, y sobre todo de tutela urgente y diferenciada reconocida por el Tribunal Constitucional del Perú y los tratados e instrumentos internacionales, que exhortan a los Estados a implementar medidas que eliminen la violencia contra la mujer. Sin perjuicio de ello, al ser medidas temporales, pueden modificar o variarse, de ser el caso, cuando la información contenida en las fichas antes mencionadas no se corrobora con los actos de investigación que se practiquen o cambien las circunstancias del caso.

3. En los casos de nivel severo 1 y severo 2 de violencia, a fin de imponerse medidas de protección, se requerirá la consideración de las pericias que se tengan a la vista, e incluso los informes psicológicos emitidos por el Centro de Emergencia Mujer (adscrito al Ministerio de la Mujer y Poblaciones Vulnerables) 
para verificar que la violencia denunciada se corrobore con las conclusiones a las que se arriba en la ficha de valoración de riesgo. Luego de ello ameritará imposición de medidas de protección más drásticas acordes al caso.

\section{REFERENCIAS}

Ayuda en Acción (2017). Tipos de violencia contra las mujeres. https://ayudaenaccion.org/ong/blog/mujer/tipos-violenciamujeres/

Cardoso, E. (2015). Mujeres y estereotipos de género en la jurisprudencia de la Corte Interamericana de Derechos Humanos. Eunomía. Revista en Cultura de la Legalidad, (9), 26-48.

Consejo de Europa (2011). Convenio del Consejo de Europa sobre Prevención y Lucha contra la Violencia contra las Mujeres y la Violencia Doméstica. Ginebra. Estambul, 11V.2011. https:// rm.coe.int/1680462543

Corte Superior de Justicia de La Libertad (2018a). Expediente n. ${ }^{\circ}$ 05098-2017-93-1601-JR-FC-02. Segunda Sala Especializada Civil de Trujillo. Trujillo: 11 de junio de 2018. https://static. legis.pe/wp-content/uploads/2018/10/Expediente-5098-2017 -93-1601-JR-FC-02-Legis.pe_.pdf

Corte Superior de Justicia de La Libertad (2018b). Expediente n. ${ }^{\circ}$ 09448-2017-70-1601-JR-FC-02. Tercera Sala Civil. Trujillo: 10 de octubre de 2018. https://static.legis.pe/wp-content/uploads/ 2019/01/Exp.-9448-2017-70-1601-JR-FC-02-Legis.pe_.pdf

Corte Superior de Justicia de La Libertad (2019). Expediente n. ${ }^{\circ}$ 13913-2018-47-1601-JR-FT-11. Trujillo: 29 de enero de 2019. https://static.legis.pe/wp-content/uploads/2019/04/Exp.-13913 -2018-47-1601-JR-FT-11-Legis.pe_.pdf?fbclid=IwAR1nY ghJSjPojTmuVPJ61 VZ4AglGBoQbwEqDmo6CDKQUq7 aGZht_9wOXDw 
Cuesta, D. (2014). Propuesta para evitar la revictimización de las víctimas en el delito de violación. [Tesis de pregrado, Universidad de las Américas]. http://dspace.udla.edu.ec/handle/33000/4602

Defensoría del Pueblo (2017). La Ley n. ${ }^{\circ}$ 30364, la administración de justicia y la visión de las víctimas. Serie Informe de Adjuntía. Informe n. ${ }^{\circ}$ 063-2017-DP/ADM. https://www.defensoria.gob. pe/wp-content/uploads/2018/05/Informe-de-Adjuntia-N-0632017-DP-ADM.pdf

Delgado, J. (2020). Marco conceptual y jurídico de la violencia de género. Sistema penal y violencia de género. Diploma de Postgrado en Derecho de Género (2. ${ }^{a}$ ed.), diciembre 2020.

Diario Oficial El Peruano (2016, 27 de julio). Instructivo de las fichas de valoración de riesgo. Diario Oficial El Peruano. https://observa torioviolencia.pe/wp-content/uploads/2018/06/instructivo.pdf

Gutiérrez de Piñeres, C., Coronel, E. y Andrés, C. (2009). Revisión teórica del concepto de victimización secundaria. Liberabit, 15(1), 49-58. http://www.scielo.org.pe/scielo.php?script=sci_ arttext\&pid=S1729-48272009000100006

Márquez, D. (2018). Las medidas de protección de la Ley 30364 y los efectos jurídicos en las víctimas de violencia familiar, Corte Superior de Lima 2017. [Tesis para obtener el título profesional de abogada, Universidad César Vallejo]. https://hdl.handle. net/20.500.12692/50828

Mateo, G. (2020). Uso indiscriminado de las fichas de valoración de riesgo para acreditar violencia familiar en el Centro de Emergencia Mujer, Huánuco-2018. [Tesis de pregrado, Universidad de Huánuco]. http://repositorio.udh.edu.pe/bitstream/ handle/123456789/2549/Mateo\%20Celis\%2c\%20Gavimaela. pdf? sequence $=1$ \&isAllowed $=y$ 
Mertens de Wilmars, F. (s. f.). Igualdad, equidad y paridad: semejanzas y diferencias conceptuales. Feminismo y derecho. Universidad de Jaén.

Naciones Unidas (1948). Declaración Universal de Derechos Humanos. https://www.un.org/es/about-us/universal-declaration-ofhuman-rights

Naciones Unidas (1979). Convención sobre la Eliminación de Todas las Formas de Discriminación Contra la Mujer. https://www. ohchr.org/sp/professionalinterest/pages/cedaw.aspx

Navarro, K. (2020). La ficha de valoración del riesgo y su relevancia para la expedición de las medidas de protección otorgadas a mujeres víctimas de violencia física. https://lpderecho.pe/fichade-valoracion-del-riesgo-proteccion-victimas-violencia-fisica/

OAS (1994). Convención Interamericana para Prevenir, Sancionar y Erradicar la Violencia contra la Mujer. «Convención de Belém do Pará». https://www.oas.org/juridico/spanish/tratados/a-61.html

Real Academia Española (s. f.). Tutela diferenciada. En Diccionario panhispánico del español jurídico. https://dpej.rae.es/lema/tuteladiferenciada

Sociedad Vasca de Victimología (s. f.). Diccionario Abierto de Términos Victimológicos. https://www.sociedadvascavictimologia. org/diccionario-1

Tribunal Constitucional del Perú (2020). Exp. n. ${ }^{\circ}$ 03378-2019-

PA/TC. Lima: 5 de marzo de 2020. https://tc.gob.pe/jurispru dencia/2020/03378-2019-AA.pdf

Varona, G., De la Cuesta, J. L., Mayordomo, V. y Pérez, A. I. (2015). Victimología: un acercamiento a través de sus conceptos fundamentales como herramientas de comprensión e intervención. https://www.ehu.eus/documents/1736829/2010409/Manual+de+Victimologi\%CC\%81a+2015.pdf 